\title{
Light Intensity of a Quartz Mercury Lamp.
}

D. TSUNESABURO ASADA, of the Shiomi Institute of Physical and Chemical Research, Osaka, Japan, has sent us an interesting communication describing measurements he has made on the intensity of the light emitted by a quartz mercury lamp. The instantaneous values of the light intensity at several points of the luminous part of an alternating current quartz mercury lamp, the terminal voltage, and the current were all measured by the help of an

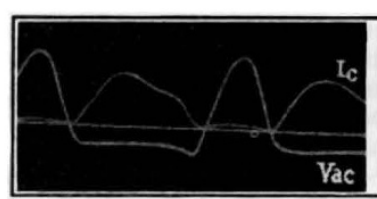

FTG. 1.

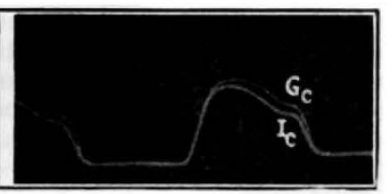

Fro. 2. oscillograph. In carrying out the test, the image of the lamp was projected by means of a lens on to a screen.

The intensity of the light on each part of the image was found by a vacuum cesium photoelectric tube. The photoelectric current was first amplified by a triode, which was found to give no deformation of the shape of the current wave.

In Fig. 1 an oscillogram is shown of the current $I_{0}$ flowing in one of the anodes $C$ and the terminal voltage $V_{a c}$ across it. This oscillogram shows clearly that so long as there is an appreciable current through the electrode, its terminal voltage is practically constant.

Fig. 2 is an oscillogram of the current $I_{c}$ and the intensity of the light $G_{c}$ in the neighbourhood of the anode $C$. From these two oseillograms it is concluded that so long as the terminal voltage is constant the intensity of the light emitted is directly porportional to the current.

A special direct current mercury lamp was made of transparent fused quartz which could be used at various current densities. The light intensity of the lamp was measured by a monochrometer and a vacuum photoelectric tube. It was found that the relation between the intensity of the light $G$, the current $I$, and the potential difference $V$ between the anode and the cathode could be expressed by a formula of the form

$$
G=\not k I\left(V-V_{0}\right)^{n}
$$

where $k$ and $V_{0}$ are constants.

$V_{0}$ is the least potential difference between both the electrodes required to maintain the arc, and is a constant for a given lamp. For a given wave-length, the number $n$ is constant.

It was found by plotting eurves having $\log (G / I)$ as ordinates and $\log \left(V-V_{0}\right)$ as abscissæ that, provided the potential difference was not very small, the resulting curve was a straight line. The formula is an experimental one. It shows that when the temperature of the mercury vapour is raised by increasing the terminal voltage, the radiations of longer wave-length increase much more rapidly than those of shorter wave-length. This radiation, therefore, follows quite a different law from black-body radiation.

Experiments with the alternating current mercury lamp show that the formula given above still holds, provided we take the mean value of the light intensity, the effective potential difference between one of the anodes and the cathode, and the effective value of the input current. The value of $n$, however, is different from that for the direct current mercury lamp.

\section{Marine Biology in Madras and Ceylon.}

THEE Administrative Report for the year 1928-29 of the Madras Fisheries Department, by Dr. B. Sundara Raj, Director of Fisheries, Madras (Report No. 1 of 1930, Madras Fisheries Bulletin, vol. 24, 1930), embraces a large variety of subjects. Part 1 describes the activities of the Department, including marine and estuarine fisheries, inland food fishes, pearl and chank fisheries, biological specimen supply, antimalarial and socio-economic work, and fish industries. Part 2 deals with finance, Part 3 with staff and equipment, with various appendices. The importance of investigation relating to food fish is emphasised as being the primary object of a scientific department of fisheries. It is evident that here great difficulties are encountered from lack of proper accommodation and staff; nevertheless, it is shown that progress is being made. Research on marine fisheries was undertaken by the trawler Lady Goschen, and on three shore stations at West Hill (Calicut), Krusadai Island, and Vizagapatam, the first two stations being provided with small laboratories; and at the Madras Aquarium laboratory work is being done on the early stages of the edible oyster. Survey of fishing banks and experimental trawling was earried on, including extensive cruises from Mangalore to Cape Comorin; fishes and certain invertebrates were identified and plankton collections made. So far only the otter trawl is used for fishing. The Danish seine could not be employed, as the motor boat originally intended for the purpose was condemned as too old for the open sea. Proposals have been made to the Government for the purchase of a small motor boat, and a drift net and long lines for surface fishing are ordered.

Investigations in the Collair Lake on the prawn
Peneopsis monoceros, the "Chakku Royya", were continued, but still little is known about the breeding grounds of this commercially important erustacean. Again the absence of staff for this work is to be regretted. Deep-water tank fishing in the Mopad Reservoir was satisfactory, a backwater net from Ennore, drift nets, and long lines being used with good results. Fish breeding and stocking experiments appear to have been unsuccessful for various reasons. Pearl oysters still continue to make sudden appearances and disappearances. It is proposed to undertake extensive research connected with this subject when the Krusadai Biological Station is instituted; meanwhile regular inspection of the pearl banks goes on, and any spat-falls will be noted.

The Fisheries Training Institute, Calieut, provides courses of study in the elements of navigation and handling of sailing boats, with classes in fish-curing, and pupils are on the increase.

The Administration Report of the Marine Biologist of Ceylon for 1929 (Part 4-Education, Science, and Art (G). July 1930), by Dr. Joseph Pearson, contains information on the pearl fishery, Gulf of Manaar, the window-pane oyster fishery and chank fisherjes, with fishery statistics, report of the second assistant marine biologist and of the marine superintendent.

The year 1929 was unfortunate for several reasons, and the absence of Dr. Pearson made it necessary to abandon the inspection of the new paar which was discovered in the region of Twynam's Paar, and which in the previous February and March was densely covered with oyster spat for a considerable part of its area of some 30 square miles. The usual survey of the Pedro and Wadge Banks was also abandoned.

No. 3198, VoL. 127] 
In Novernber, however, a portion of the area off 'Chilaw was examined by a running survey by dredge for the purpose of charting the paar area, and a chart is given with the present report. In this charting no idea can be given of the number of oysters present, but a picture is provided of the general limitations of the paar ground and the general slope of the area. It also shows the nature of the paar and will indicate the presence of oysters, although small patches of oysters may be missed. Current observations on the main Pearl Banks were continued. There is a westerly trend in all currents which would tend to take all pelagic oyster larva present when the observations were made out into the deep water, where they would be lost.

Dr. Pearson has obtained all particulars for a new boat to take the place of M.L. Lion, which has been condemned. The new boat is to be of the modern Scotch type of fishing boat, with a length of 45 feet, beam 13 feet 6 inches, draught 5 feet 6 inches.

\section{Afforestation in New Zealand.}

TIHAT private companies have been formed in New Zealand to promote afforestation work is well known. Many of these companies have now been federated into the New Zealand Timber Growers' Association, which publishes an official quarterly known as the Timber Growers' Quarterly Review, the second number (for September last) of which has recently appeared. This number deals primarily with reports, ete., of the 1930 Conference of the member companies of the Association.

The attitude of the companies towards this new national industry and the aims and objects of the latter are well portrayed and merit a close study in Great Britain. The member companies in the Association now represent a combined capital of $£ 5,000,000$. "Afforestation in a minor way", it is truly said. "is practically useless and would really mean nothing whatever either to New Zealand or the Empire; and although the companies represented in the Association to-day have joint afforestation schemes in hand comprising over 250,000 acres, the desired objective is a million acres of exotics." The magnitude of the task can be readily appreciated, as also the value of combining.

The delegates to the Conference had the opportunity of meeting the Prime Minister, Hon. G. W. Forbes, who has recently been at the Imperial Conference in London, and the Minister responsible for the N.Z. Forest Department, the chief matter under discussion being the important one of future co-operation in research work. Here the Association is taking the broadest views. The president, Mr. W. Fraser, in discussing the question with the Minister, pointed out that while the Association "had planned in the first instance to establish its own arms of research, the successful functioning during the past 12 months of the Biological Committee, to which not only the Association but also the Bureau of Scientific and Industrial Research, the Cawthron
Institute, the Sawmillers' Federation, and the Forestry Department had contributed brains and money, had indieated the possibility of still further co-operation in matters that are equally of joint interest and joint advantage".

The New Zealand Timber Growers" Association is said to consist largely of business men who may be regarded as trained executives and organisers. It also embodies technical forestry men of wide and sound experience and established judgment. It regards research as being a most important and vital adjunct or partner of business, and is prepared to forward energetically and substantially to endow useful research along business lines in the interests of afforestation. This was the message of the 1930 Conference.

There was no attempt on the part of the Conference to minimise the value of the work (much of it of an experimental nature) of the State Forest Service during the past quarter of a century. Far otherwise. But the importance of the provision of a large volume of softwood timber, which it has been shown can be grown on large areas of available land, has been fully realised; also that this work, to be done expeditiously, is a purely business proposition, quite outside the capacity of a State Department, which could not be granted the funds from the public purse to carry it on with such rapidity.

The realisation of this fact and the coming of the private companies, run on investors' capital, is remarkable and furnishes evidence of a shrewd foresight on the part of the Now Zealanders. Not less remarkable, if we compare it with the reduplication of research work in different institutes and so forth in Great Britain, is the swift recognition by the leaders of the Association that co-o eration in research with the existing centres would be the most practical step to take, instead of bringing into being new and independent ones.

\section{Archæological Investigation in Oregon, U.S.A.}

$\mathrm{R}^{\mathrm{E}}$ ESULTS of archrological investigation on the middle Columbia River undertaken by the University of California in 1924-26 are recorded by W. D. Strong, W. E. Schenck, and J. H. Stewart in the University's Publications in American Archoology and Ethnology, vol. 29, pt. 1, under the title "Archrology of the Dalles-Deschuttes Region". This area was chosen for investigation as the geographical and economic conditions at this point of the river are such as to have made it one of great importance to primitive man, and it must have been occupied from a remote period.

Seven distinct types of evidence were exposed, these including the Wakemap Mound, village sites on Miller's Island, burials - cremation and pre-and postCaucasian inhumations-as well as numerous petrographs. Of these, the most important were the mound, on account of the depth of the deposit con- taining evidence of occupation, and the cremation burials, on account of the richness of their culture. It was noted that the culture of the cremation burials was quite distinct in character from that of the mound, the former being of an entirely ceremonial and omamental character, while the objects from the mound were entirely utilitarian. On the whole, however, there was good reason to think the two are connected, and to regard them as representing two sides of a single culture. It is also suggested that the old type conical, semi-subterranean house is connected with the mound eulture, but that connexion is not yet proved.

It seems probable that most of the rock carvings are to be associated with the mound and crema tion culture, most of them being attributed to the Wakemap people. There is a lack of relationship between the post-Caucasian burials and the mound and

No. 3198 , VoL. 127] 